I. Jurić ${ }^{1, a}$, I. Garašić ${ }^{1}$, Z. Kožuh ${ }^{7}$, J. Eržišnik ${ }^{7}$, D. Uđbinac

\title{
Primjena dupleks čelika za aditivnu proizvodnju električnim lukom i žicom
}

Originalni naučni rad / Original scientific paper Rad je u izvornom obliku objavljen u Zborniku sa 4. IIW Kongresa zavarivanja Jugoistočne Evrope „Safe Welded Construction by High Quality Welding" održanog u Beogradu 10-13. Oktobra 2018

Rad primljen / Paper received:

Jul 2019.

Ključne reči: aditivna proizvodnja električnim lukom žicom, WAAM, MAG zavarivanje, dupleks

\section{Sažetak}

Aditivna proizvodnja električnim lukom i žicom novi je koncept proizvodnje zasnovan na izradi metalnih komponenti dodavanjem materijala sloj po sloj. $U$ usporedbi s konvencionalnim proizvodnim tehnologijama, aditivna proizvodnja omogućuje značajne uštede u materijalu, što je naročito izraženo kod skupih materijala kao što su dupleks nehrđajući čelici. Izrada uzoraka aditivnom proizvodnjom električnim lukom i žicom izvršena je uporabom konvencionalnog MAG postupka zavarivanja. Stabilnost procesa je bila glavni kriterij za određivanje optimalnih parametara zavarivanja. Kako bi se ispitao utjecaj zaštitnog plina, uzroci od dupleks čelika izrađeni su uz upotrebu četiri različite plinske mješavine. Na uzorcima je ispitana kvaliteta površine, homogenost i postignuta mikrostruktura izrađene komponente.

\section{Uvod}

$U$ današnjem vremenu sveprisutne globalizacije gdje je izražena velika dostupnost informacija, znanja, roba i usluga, ali i prisutna izuzetno velika konkurencija, povećanje kvalitete proizvoda, fleksibilnost pri razvoju i proizvodnji te racionalizacija troškova nužni su uvjeti za opstanak na tržištu. Uz sve navedeno, važno je spomenuti konstantno povećanje potrošnje visokokvalitetnih materijala čija proizvodnja zahtjeva velike količine energije i značajna financijska sredstva. Navedene činjenice dovode do zaključka da je razvoj novih proizvodnih tehnologija neophodan. Kao jedan od rezultata tog razvoja pojavljuje se novi koncept proizvodnje, aditivna proizvodnja.

Aditivna proizvodnja proizvodni je postupak koji se bazira na nanošenju čestica materijala sloj po sloj. Postupak omogućuje pretvorbu ideje u gotov proizvod u kratkom vremenu uz uštedu materijala i eliminaciju međukoraka poput izrade posebnih alata ili kalupa, zamjene alata itd.
Adresa autora / Author's address:

Sveučilište u Zagrebu Fakultet strojarstva i brodogradnje, Ivana Lučića 5, Zagreb, Hrvatska

aivan.juric@fsb.hr

Key words: wire arc additive manufacturing, WAAM, MAG welding, duplex

Povijesno gledajući, suvremeni postupci aditivne proizvodnje prošli su nekoliko faza s obzirom na njihovu primjenu. $U$ početku primjene ti su se

postupci uglavnom koristili za brzu izradu prototipova. Pojam „brzo“ treba shvatiti uvjetno jer je za proizvodnju potrebno od nekoliko minuta do nekoliko dana. Međutim, uspoređujući s klasičnom proizvodnjom, ukupno trajanje proizvodnog ciklusa kod aditivne proizvodnje je kraće. Proizvodi načinjeni tim postupcima uglavnom su se rabili za unapređivanje procesa razvoja proizvoda [1].

Kako je vrijeme ključ uspjeha na tržištu, iznimno je važno što ranije plasirati proizvod na tržište. Ranijim izlaskom na tržište ostvaruje se prednost nad konkurencijom u smislu definiranja cijene proizvoda. Također, raniji izlazak na tržište nudi bolje marketinške prilike i brži povrat sredstava uloženih u razvoj. Budući da aditivna proizvodnja skraćuje vrijeme od ideje do plasiranja gotovog proizvoda na tržište, nameće se kao vrlo perspektivan proizvodni postupak u budućnosti. Činjenica da u moderno doba, uz smanjenje vremena izrade, životni vijek proizvoda opada, nameće zaključak da je potrebno dodatno razvijati fleksibilne proizvodne sustave.

Područje primjene aditivne proizvodnje vrlo je široko, od proizvoda široke namjene preko automobilske i zrakoplovne industrije do arhitekture. $U$ automobilskoj i zrakoplovnoj industriji aditivni postupci omogućuju izradu metalnih dijelova složene geometrije. Ti su dijelovi često manje mase i boljih karakteristika nego dijelovi proizvedeni klasičnim proizvodnim postupcima. Sa stajališta uštede energije i smanjenja emisije štetnih plinova svako olakšanje konstrukcije je poželjno s obzirom da broj automobila i zrakoplova neprestano raste. Aditivna je proizvodnja efikasan način izrade dijelova od skupih materijala poput titana i nikla i njihovih legura koji se primjenjuju u zrakoplovnoj industriji. Mogućnost potpune automatizacije procesa aditivne proizvodnje iz 
modela što omogućuju CAD/CAM sustavi, čime se smanjuje vrijeme proizvodnje i ljudski rad, još je jedna od prednosti AM pred klasičnim postupcima. lako program za CNC stroj može biti automatski generiran iz CAD modela, za dijelove složene geometrije potrebno je nekoliko prihvata obratka čime se povećava vrijeme rukovanja, broj stezanja obratka i proces umjeravanja nakon prihvata [2].

Uz navedene prednosti, aditivna proizvodnja ima i neke nedostatke. Glavni nedostatak je kvaliteta površine koja uglavnom zahtjeva dodatnu obradu. Nadalje, dodavanje materijala sloj po sloj može uzrokovati anizotropiju mehaničkih svojstava komponente. Kod nekih postupaka aditivne proizvodnje metala izražen su problem vrlo velika zaostala naprezanja koja značajno smanjuju nosivost komponente.

Danas su mnoga istraživanja usmjerena na proizvodnju metalnih komponenti kompleksne geometrije $\mathrm{i}$ to $\mathrm{s}$ materijalima poput titana i nikla kod kojih se klasičnim metodama ne može ekonomično proizvesti geometrijski zahtijevan proizvod [2]. Kao izvori energije za aditivnu proizvodnju metalnih materijala koriste se električni luk (TIG, MIG/MAG i plazma) i zraka (laserska i elektronska), a dodatni materijal mogu biti žica i prašak.

Postupci koji koriste prašak kao dodatni materijal razvijeniji su od postupaka koji koriste žicu. Razlog tome je taj što prašak omogućava proizvodnju dijelova s vrlo visokom geometrijskom točnošću. Debljina slojeva kreće se između $20 \mu \mathrm{m}$ i $100 \mu \mathrm{m}$, a tolerancije dijelova proizvedenih ovim postupkom iznose $\pm 0,05 \mathrm{~mm}$. Glavni nedostatak postupaka koji koriste prašak za dodatni materijal je iznimno niska proizvodnost, tj. prosječni depozit materijala iznosi oko $0,6 \mathrm{~kg} / \mathrm{h}$ što ograničava proizvodnju za male dijelove [3].

Proizvodnost aditivnog postupka sa žicom puno je veća od proizvodnosti postupaka koji koriste prašak kao dodatni materijal. Također, korištenje žice kao dodatnog materijala je ekološki prihvatljivije i operateri nisu izloženi prašku koji ima potencijalno negativan utjecaj na zdravlje. Količina depozita kreće se čak do $20 \mathrm{~kg} / \mathrm{h}$ za čelike što ovaj postupak čini pogodnim za proizvodnju dijelova većih dimenzija. Žica kao dodatni materijal je višestruko jeftinija i dostupnija od praška što je značajna prednost u odnosu na postupke koji koriste prašak [3].

\section{Aditivna proizvodnja električnim lukom i žicom}

Aditivna proizvodnja električnim lukom i žicom (engl. Wire Arc Additive Manufacturing - WAAM), novi je postupak aditivne proizvodnje koja omogućava proizvodnju metalnih proizvoda navarivanjem slojeva. Postupak se prvi puta spominje 1926. godine kada Baker počinje koristiti elektrolučno zavarivanje za izradu 3D modela taloženjem rastaljenog materijala sloj na sloj [4]. Postupak omogućuje proizvodnju proizvoda blizu konačne dimenzije (engl. near net shape) i BTF (engl. Buy-to-Fly) omjer od 1,2, što rezultira značajnom uštedom materijala [2]. BTF je omjer mase sirovca i gotovog proizvoda. Poželjno je da on bude što bliži jedinici. Navedene karakteristike čine postupak pogodnim za proizvodnju komponenti većih dimenzija načinjenih od skupih materijala.

WAAM postupak koristi standardnu opremu za robotizirano zavarivanje: izvor struje, dodavač žice, pištolj za zavarivanje, robotsku ruku, kontrolnu jedinicu za upravljanje robotom itd. Pojedini materijali zahtijevaju dodatnu zaštitu u vidu korištenja zaštitne inertne atmosfere. $U$ tom slučaju potrebno je posegnuti za dodatnom opremom poput zavarivačkog šatora ili opreme za lokalnu zaštitu zavara [5].

Kao i svaki proizvodni postupak, WAAM ima svoje prednosti i nedostatke.

Prednosti [2]:

- ekonomična izrada komponenti od skupih materijala

- mogućnost automatizacije

- proizvodnja komponenti složene geometrije

- velika količina depozita

- niži troškovi proizvodnje u usporedbi s procesima baziranim na prašku

- potencijalno nema ograničenja u veličini izradaka

- mogućnost strojne obrade tijekom procesa

- mogućnost stvaranja funkcionalno profiliranog materijala

- otvorena struktura sustava omogućuje primjenu bilo kojeg proizvođača izvora struje i manipulatora.

Nedostaci $[2,6]$ :

- pojava zaostalih naprezanja i deformacija zbog visokog unosa topline

- neujednačena geometrija zavara uzduž sloja

- poroznost

- potrebna naknadna obrada odvajanjem čestica

- nedostatak iskustva u primjeni tehnologije

- teško praćenje parametara zavarivanja

- potreba za visokoobrazovanom radnom snagom (programiranje robota, CNC strojeva)

- pojedini materijali zahtijevaju zaštitnu inertnu atmosferu, pa je potrebno koristiti zaštitni šator ili lokalni uređaj za zaštitu. 
Zaostala naprezanja i deformacije podloge rezultat su velikih unosa topline i najveća su u smjeru nanošenja materijala. One utječu na tolerancije izratka i uzrokuju greške. Ukoliko struktura ne može podnijeti deformiranje, doći će do loma ili će nastati zaostala naprezanja. Postoji nekoliko metoda kojima se reduciraju utjecaji zaostalih naprezanja i pojava deformacija. Prva metoda je simetrično slaganje. Kod ove metode se postavlja ravnina simetrije u skladu s volumenom izratka. Taloženje materijal treba biti ravnomjerno i odvija se naizmjenično sa svake strane u odnosu na ravninu simetrije, tako da dok se na jedan dio nanosi novi sloj, drugi dio se hladi. Nedostatak ove metode je potreba za dodatnom obradom. Druga metoda je back to back slaganje. Ova metoda omogućava dobro upravljanje unosima topline. Koristi se kod izrade simetričnih dijelova. Prije razdvajanja dijelova cijeli izradak toplinski se obrađuje radi smanjenja zaostalih naprezanja. Sljedeća se metoda temelji na optimiranju orijentacije dijelova. Dijelovi se pozicioniraju na način da se dobiju što kraći slojevi taloženja, jer su manje deformacije i zaostala naprezanja kod kraćih prolaza. Konačno, metoda visokotlačnog valjanja koristi se za postizanje optimalne mikrostrukture i uklanjanje zaostalih naprezanja, ali ima nedostatak što je primjenjiva samo na jednostavnijim izratcima [6].

Površina izratka sastoji se od velikog broja prolaza jedan do drugoga sa ili bez preklapanja. Oblik prijelaza je nepravilan, tj. valovit. Ta valovitost se mora ukloniti naknadnim procesima obrade kako bi se eliminirale površinske nepravilnosti.

\section{Nehrđajući dupleks čelici}

Zbog relativno visoke čvrstoće dupleks čelici optimalan su izbor za konstrukcije izložene koroziji pri čemu dolazi do izražaja njihova karakteristika izvanredne kombinacije korozijske postojanosti i mehaničkih svojstava. Navedena svojstva omogućuju smanjenje nosivih presjeka i smanjenje ukupne mase proizvoda. $U$ blažem korozivnom okruženju mogu biti dovoljno dobra zamjena za puno skuplje niklove legure. $U$ odnosu na austenitne čelike, dupleks čelici imaju puno višu granicu razvlačenja. Također, viša im je i tvrdoća, a samim time i otpornost na abrazijsko trošenje [7].

Većina novijih dupleks čelika ima dobru žilavost $\mathrm{i}$ duktilnost. Zbog velikog udjela feritne faze, pri sniženju temperature naglo prelaze iz žilavog $u$ krhko područje, slično kao feritni nehrđajući čelici. Donja temperatura primjene je ograničena na -40 ${ }^{\circ} \mathrm{C}$. Gornja temperatura primjene dupleks čelika je oko $315{ }^{\circ} \mathrm{C}$, zbog brojnih mikrostrukturnih precipitata koji se mogu izlučiti na relativno niskoj temperaturi, a koji loše utječu na korozijsku postojanost i mehanička svojstva. Toplinska rastezljivost dupleks čelika slična je toplinskoj rastezljivosti ugljičnih i niskolegiranih čelika. Ova podudarnost omogućava njihovo međusobno spajanje u nekim proizvodima (npr. tlačne posude) bez opasnosti od pojave prevelikih naprezanja pri kasnijem zagrijavanju tijekom eksploatacije [7].

Mikrostruktura dupleks čelika je dvofazna i sastoji se od približno $50 \%$ volumnih udjela ferita i austenita. Optimalna kombinacija austenita i ferita varira ovisno o proizvođačima i kreće se između 45 $\%$ i $60 \%$ austenita u mikrostrukturi.

\section{Eksperiment}

Eksperiment je proveden na Fakultetu strojarstva i brodogradnje Sveučilišta u Zagrebu. Određena je odgovarajuća tehnologija za aditivnu proizvodnju električnim lukom i žicom dupleks nehrđajućeg čelika pomoću MAG postupka te je ispitan utjecaj zaštitnog plina na kvalitetu površine i mikrostrukturu izrađenog uzorka.

Zavarivanje uzoraka provedeno je pomoću robotske stanice Almega OTC AX V6. Korištena robotska ruka ima šest rotacijskih stupnjeva slobode gibanja na osnovi kojih je u pripadajućem radnom prostoru moguće postići precizno pozicioniranje i orijentiranje pištolja za zavarivanje. U sastavu robotske stanice nalazi se korišteni izvor struje Varstroj VPS 4000.

Za izradu uzoraka korišten je dodatni materijal oznake G $2293 \mathrm{NL}$ prema EN ISO 14343 A promjera $1,2 \mathrm{~mm}$. Kemijski sastav materijala prikazan je u tablici 1.

\begin{tabular}{|c|c|c|c|c|c|c|}
\hline $\begin{array}{c}\text { Legirni } \\
\text { element }\end{array}$ & $\mathrm{C}$ & $\mathrm{Si}$ & $\mathrm{Mn}$ & $\mathrm{Ni}$ & $\mathrm{Cr}$ & $\mathrm{Mo}$ \\
\hline $\begin{array}{c}\text { Maseni } \\
\text { udio, \% }\end{array}$ & 0,009 & 0,370 & 1,630 & 8,76 & 22,8 & 3,150 \\
\hline $\begin{array}{c}\text { Legirni } \\
\text { element }\end{array}$ & $\mathrm{Cu}$ & $\mathrm{Co}$ & $\mathrm{S}$ & $\mathrm{P}$ & $\mathrm{N}$ & \\
\hline $\begin{array}{c}\text { Maseni } \\
\text { udio, \% }\end{array}$ & 0,050 & 0,028 & 0,001 & 0,013 & 0,1405 & \\
\hline
\end{tabular}


Tablica 1. Kemijski sastav dodatnog materijala [8]

Kao podloga za izradu uzoraka korišten je lim od nehrđajućeg čelika oznake AISI 304 debljine $8 \mathrm{~mm}$, dimenzija $300 \mathrm{~mm} \times 40 \mathrm{~mm}$. U eksperimentu su korištene četiri mješavine zaštitnih plinova s ciljem otkrivanja njihovih utjecaja na kvalitetu i svojstva uzoraka. $U$ tablici 2 . navedene su korištene mješavine zaštitnih plinova i njihov sastav.

\begin{tabular}{|l|c|c|c|c|c|}
\hline \multirow{2}{*}{$\begin{array}{c}\text { Naziv } \\
\text { proizvoda }\end{array}$} & \multirow{2}{*}{$\begin{array}{c}\text { Grupa po } \\
\text { ISO 14175 }\end{array}$} & \multicolumn{4}{|c|}{ Volumni udio, \% } \\
\cline { 3 - 6 } & $\mathrm{Ar}$ & $\mathrm{O}_{2}$ & $\mathrm{CO}_{2}$ & $\mathrm{~N}_{2}$ \\
\hline Inoxline N2 & $\mathrm{N} 2$ & 97,5 & & & 2,5 \\
\hline Inoxline X3 & $\mathrm{M} 13$ & 97 & 3 & & \\
\hline Inoxline C2 & $\mathrm{M} 12$ & 97,5 & & 2,5 & \\
\hline $\begin{array}{l}\text { Ferroline } \\
\text { C6X1 }\end{array}$ & $\mathrm{M} 24$ & 93 & 1 & 6 & \\
\hline
\end{tabular}

Tablica 2. Mješavine zaštitnih plinova [9]

Putanja gibanja pištolja za zavarivanje izbjegavanje uspostave električnog luka na jednoj naizmjenično je mijenjala smjer, dakle, jedan prolaz strani. Takav bi način izrade uzoraka doveo do je zavaren s lijeva na desno, a drugi s desna na velikih razlika u visinama između jedne i druge lijevo kako je i prikazano na slici 1. Razlog tome je strane uzorka.

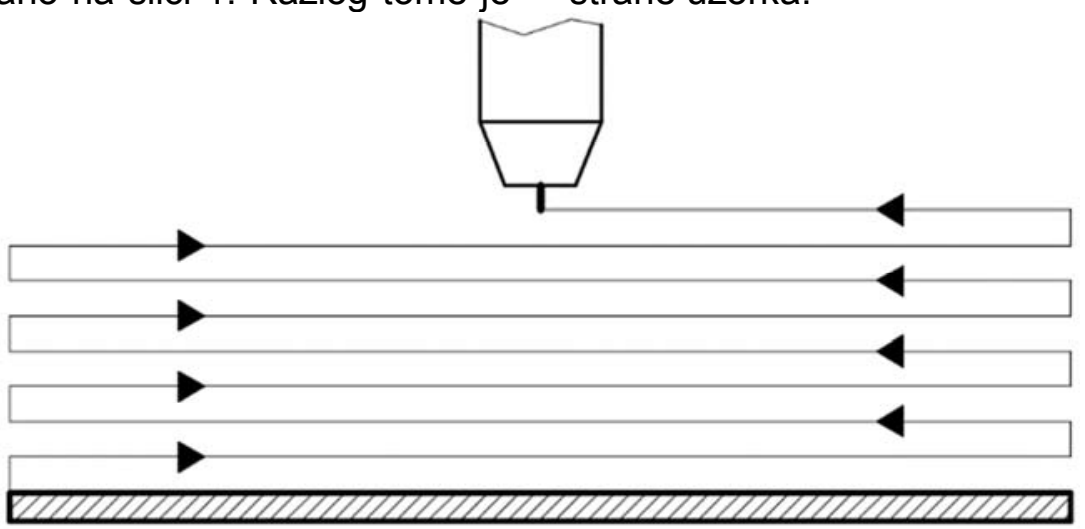

Slika 1. Trajektorije putanja alata [9]

U prvoj fazi eksperimenta određeno je optimalno područje parametara $s$ obzirom na stabilnost procesa. Tijekom izrade uzoraka očitavani su parametri zavarivanja i mjerena je visina pomičnim mjerilom nakon svakog prolaza. Prije svakog prolaza mjerena je temperatura beskontaktnom metodom uređajem Fluke IR Thermometer. Temperatura između prolaza držana je ispod 100
${ }^{\circ} \mathrm{C}$. Prijenos metala u sva četiri stanja pokusa bio je kratkim spojevima, a nagib pištolja bio je neutralan. Protok plina kod sva četiri stanja pokusa iznosio je $19 \mathrm{l} / \mathrm{min}$, slobodni kraj žice $10 \mathrm{~mm}$, a brzina zavarivanja $27 \mathrm{~cm} / \mathrm{min}$. Prosječni parametri zavarivanja za svaki od uzoraka prikazani su u tablici 3. Konačan izgled uzorka vidljiv je na slici 2.

\begin{tabular}{|c|c|c|c|c|}
\hline Uzorak & $\begin{array}{c}\text { Prosječna } \\
\text { jakost struje, } \\
\text { A }\end{array}$ & $\begin{array}{c}\text { Prosječni } \\
\text { napon, } \mathrm{V}\end{array}$ & $\begin{array}{c}\text { Prosječni } \\
\text { unos topline, } \\
\mathrm{kJ} / \mathrm{cm}\end{array}$ & $\begin{array}{c}\text { Prosječna } \\
\text { visina } \\
\text { slojeva, mm }\end{array}$ \\
\hline N2 & 133 & 17 & 4,0 & 2,14 \\
\hline X3 & 150 & 17,3 & 4,6 & 2,07 \\
\hline C2 & 149 & 17,2 & 4,6 & 2,07 \\
\hline C6X1 & 150 & 17,2 & 4,6 & 2,00 \\
\hline
\end{tabular}

Tablica 3. Prosječni parametri zavarivanja i prosječna visina slojeva [9] 


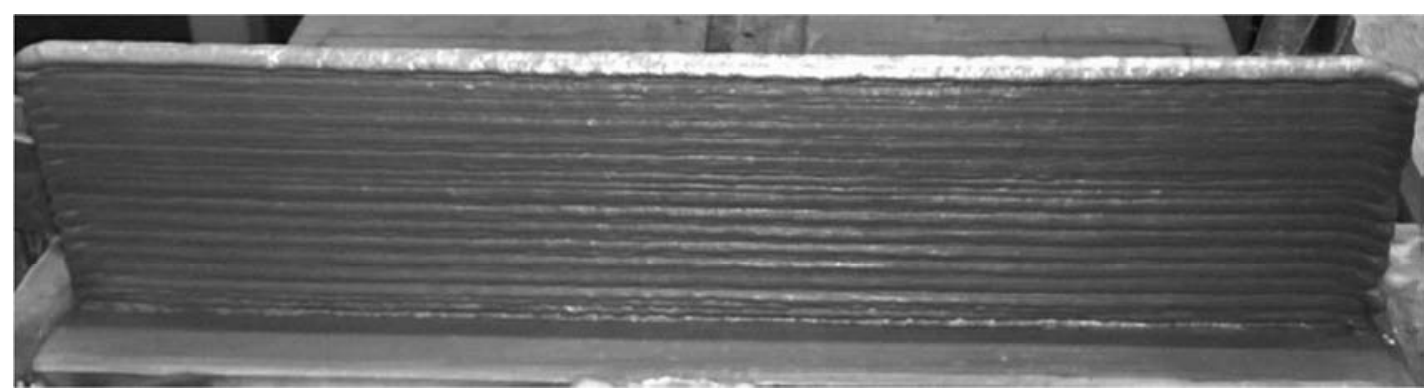

Slika 2. Konačni izgled uzorka [9]

Nakon provedenog zavarivanja iz uzoraka su izrezani makroizbrusci čija je površina nakon finog brušenja i poliranja nagrižena u 10 postotnoj

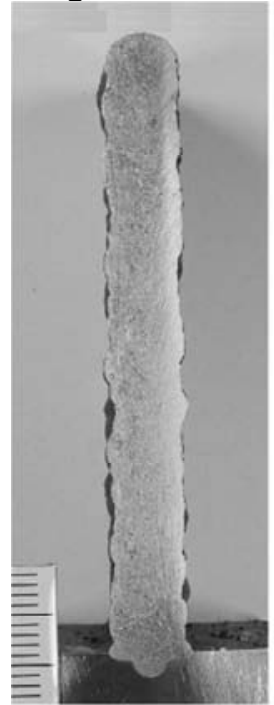

$\mathrm{C} 2$

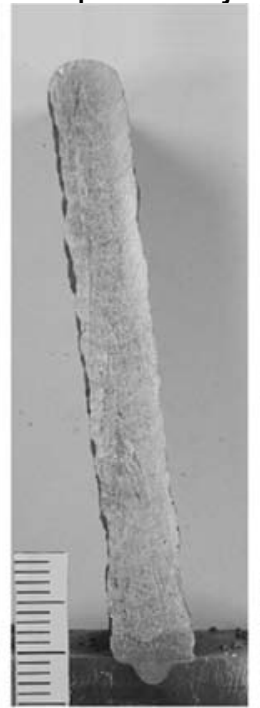

C6X1 oksalnoj kiselini pri naponu od $8 \mathrm{~V}$ i jakosti struje od 6 A u trajanju od 60 sekundi. Na slici 3 prikazani su makroizbrusci uzoraka.

Slika 3. Makroizbrusci uzoraka [9]

Analizom makrostrukture nisu uočene nikakve nepravilnosti ni u jednom od uzoraka. Struktura uzoraka je ujednačena i homogena bez vidljivih uključaka i poroznosti. Stabilan proces i malo odstupanje parametara rezultirali su ujednačenom širinom slojeva na uzorcima. Makroanaliza je također pokazala da postoji potencijalna razlika $u$ mikrostrukturi između završnog sloja na vrhu uzorka i središnjih slojeva.

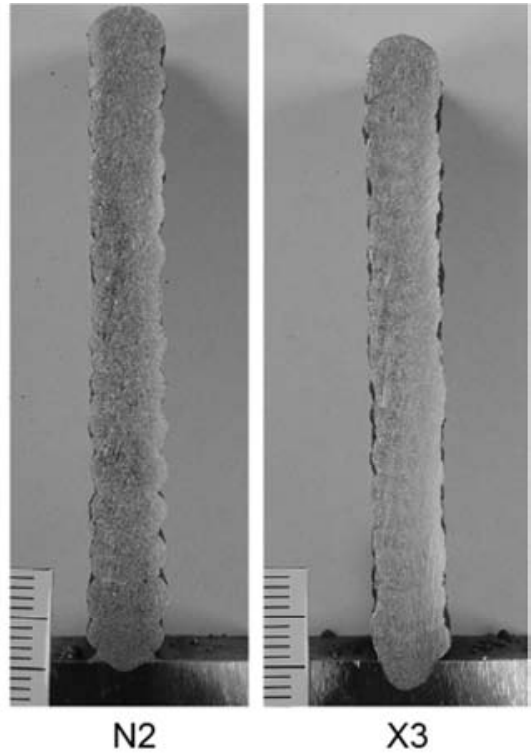

$\mathrm{Na}$ izrađenim uzorcima provedeno je ispitivanje teksture površine tako da je iz svakog uzorka pomoću 3D skenera najprije skenirana bočna ispitna površina dimenzija $50 \mathrm{~mm} \times 50 \mathrm{~mm}$. Korišteni skener je David SLS 2 te pripadajući softver DAVID 3. Dobivene digitalne slike potom su obrađene pomoću softvera MountainsMap. Rezultati obrade prikazani su na slikama 4, 5, 6 i 7. Parametri teksture površine ispitani su prema normi ISO 25178 te prikazani u tablici 4.,

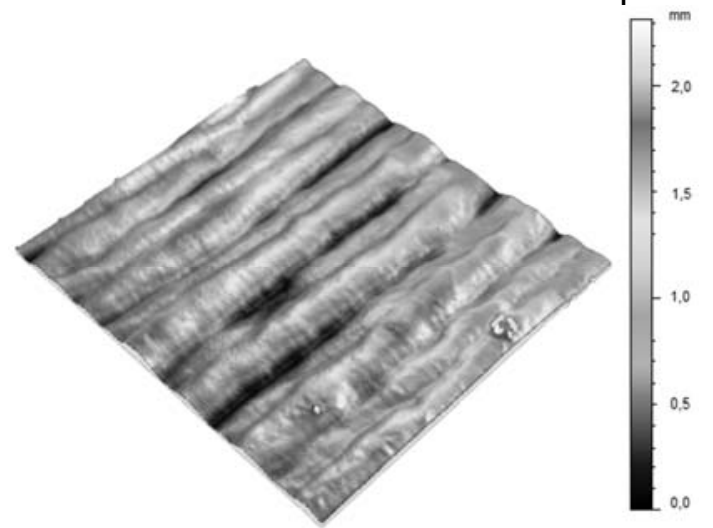

Slika 4. Tekstura dijela bočne površine uzorka N2 


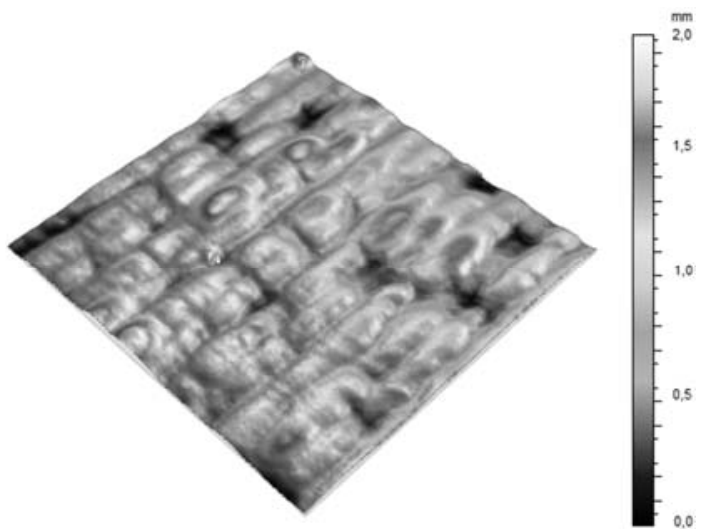

Slika 5. Tekstura dijela bočne površine uzorka X3

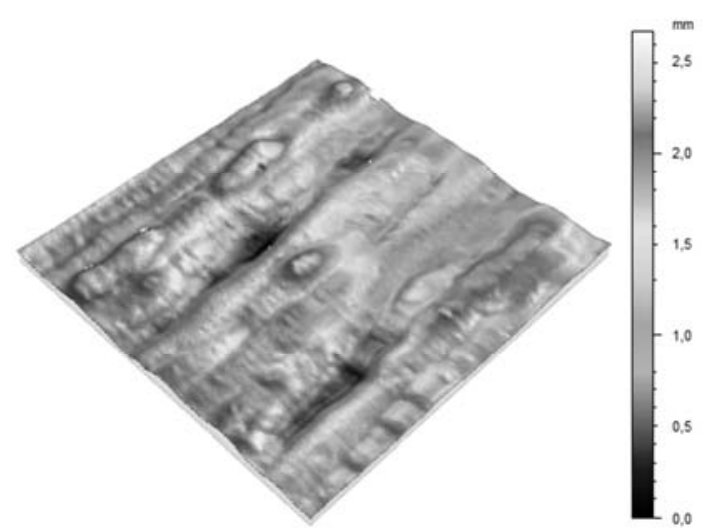

Slika 6. Tekstura dijela bočne površine uzorka C2

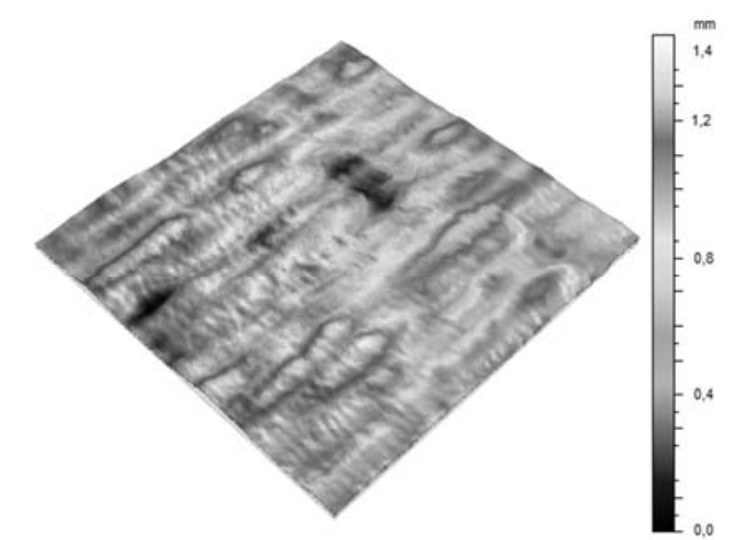

Slika 7. Tekstura dijela bočne površine uzorka C6X1

\begin{tabular}{|c|c|c|c|c|}
\hline Parametar & N2 & X3 & C2 & C6X1 \\
\hline$S_{a}$ & 0,287 & 0,244 & 0,362 & 0,194 \\
\hline$S_{q}$ & 0,355 & 0,308 & 0,448 & 0,245 \\
\hline$S_{z}$ & 2,32 & 1,97 & 2,68 & 1,45 \\
\hline
\end{tabular}

Tablica 4. Parametri teksture ispitanog dijela površine uzoraka

Ispitana su tri osnovna parametra teksture površine: srednje aritmetičko odstupanje površine $S_{a}$ (pandan uobičajeno korištenom parametru hrapavosti $R_{a}$ ), kvadratni korijen prosječnih korijena visine površine $S_{q}$ i raspon neravnina površine $S_{z}$ [10]. Pregledom izračunatih parametara jasno se može vidjeti da je tekstura uzorka C2 najnepravilnijeg oblika $s$ izraženom valovitošću. Najmanja valovitost zabilježena je kod uzorka C6X1.

Kako su parametri teksture bočne površine uzoraka izračunati na temelju relativno malog dijela uzorka, treba ih uzeti $s$ rezervom jer potencijalno u sebi sadrže relativno veliku grešku mjerenja. Navedene vrijednosti parametara su stoga samo indikativne za razlike između istraženih skupova podataka i ne mogu se uzeti u obzir kao statistički značajni pokazatelji ukupne učinkovitosti primijenjene tehnologije aditivne proizvodnje električnim lukom i žicom.

\section{Zaključci}

$\mathrm{Na}$ temelju provedenog istraživanja može se zaključiti da je dupleks nehrđajući čelik oznake G 2293 NL prema EN ISO 14343 A primjenjiv za postupak aditivne proizvodnje električnim lukom i žicom. Korišteni parametri rezultirali su stabilnim procesom i zadovoljavajuće ujednačenom geometrijom slojeva. Kod uzorka N2 ostvarena je najveća prosječna visina slojeva unatoč najmanjem 
primijenjenom unosu topline. To se objašnjava najmanjim gubitkom materijala odnosno najmanjim rasprskavanjem prilikom korištenja zaštitnog plina $s$ $2,5 \% \mathrm{~N}_{2}$. Analiza makrostrukture pokazala je homogenu strukture bez vidljivih nepravilnosti. Ispitivanjem teksture bočne površine uzoraka najveća je valovitost utvrđena kod uzorka C2, a najmanja kod uzorka C6X1. lako je uvjerljivo najmanje rasprskavanje zabilježeno kod uzorka N2,

\section{Literatura}

[1] Godec D., Šercer M., „Aditivna proizvodnja“, Fakultet strojarstva i brodogradnje, Zagreb, 2015.

[2] Ilić D., „Optimizacija prijenosa metala za aditivnu proizvodnju električnim lukom i žicom", Diplomski rad, Fakultet strojarstva i brodogradnje, Zagreb, 2016.

[3] Ding D., Pan Z., Cuiuri D., Li H., „Wire-feed additive manufacturing of metal components: technologies, developments and future interests", International Journal Advanced Manufacturing Technology, pp. 465-481, 2015.

[4] Wiliams S., WAAMMat team, "Large Scale Metal Wire + Arc Additive Manufacturing of Structural Engineering Parts“, Cranfield University, 2016.

[5] Martina F., Williams S., „Wire + arc additive manufacturing vs. traditional machining from solid: a cost comparation“, Welding Engineering and Laser Processing Centre, Cranfield University, 2015. parametri teksture površine tog uzorka pokazali su značajnu razinu nepravilnosti u usporedbi s drugim uzorcima.

Makroanalizom je utvrđena potencijalna razlika u mikrostrukturi između završnog sloja na vrhu uzorka i središnjih slojeva, pa će buduće istraživanje biti usmjereno na detaljno ispitivanje mikrostrukture i mehaničkih svojstava uzoraka.

[6] Williams S. W., Martina F., Addison A. C., Ding J., Pardal G., Colegrove P., „Wire + Arc Additive Manufacturing", Materials Science and Technology, 2016.

[7] Rede, Vera, „Utjecaj mikrostrukture zavara dupleks čelika na otpornost prema trošenju“, Doktorski rad, Fakultet strojarstva i brodogradnje, Zagreb, 2004.

[8] http://www.migweld.de/english/products/stainles s-steel-welding-wire/4462-ml-2293-nl/

Dostupno: 1. 7. 2017.

[9] Uđbinac, D., „Primjena dupleks čelika za aditivnu proizvodnju električnim lukom i žicom", Diplomski rad, Fakultet strojarstva i brodogradnje, Zagreb, 2017.

[10] Thompson, A., Senina, N., Maskeryc, I., Körnera, L., Lawesa, S., Leacha, R., „Internal surface measurement of metal powder bed fusion parts“, Additive Manufacturing, vol. 20, pp. 126-133, 2018. 